\title{
Elementos sociais para a compreensão do prestígio científico e de seus riscos
}

\author{
Washington Luiz Pacheco de Carvalho*
}

Artículo recibido: 13-05-2011 y aprobado: 15-06-2011

Social elements for the comprehension

of the scientific status and its risks

Resumo: As ciências gozam de grande prestigio na opinião popular. Seus sucessos, tornados públicos principalmente pela via tecnológica, lhe conferem credibilidade, apoio incondicional e expectativas populares positivas. Ademais, em geral, sua ampla aceitação leva as pessoas a desenvolverem apenas idéias positivas sobre cientistas e sobre o funcionamento da ciência, as quais são reforçadas nas escolas. Por outro lado, a história da ciência tem permitido a compreensão de relações sociais internas e externas à ciência, evidenciando-a como um campo de disputas, interesses e contradições como tantos outros que envolvem relações humanas. Assim, o objetivo deste texto é o de fornecer elementos sociais da construção e impactos das ciências naturais, com o intuito de se evidenciar a importância dos estudos sociais sobre o mundo científico para os cursos de formação de professores de ciências.

Palavras chave: Relações sociais nas ciências, imagem pública das ciências, cientificismo.

Abstract: Natural sciences have an enormous status in public opinion. Their achievements, which become known mostly by means of technology, give to them social credibility, unconditional support and positive social expectances. Further, their social images, generated by the success of their products, tend to lead people to develop only favorable ideas about scientists and about how science works, which are even more reinforced in the schools. By another side, the history of science has been allowed us to comprehend the internal and external social relations concerning to science, showing it as a field of disputes, interests and contradictions as many other fields which comprise human relations. Therefore, the objective of this text is to present social elements of the construction and impacts of natural science, aiming at putting in evidence the importance of the social studies of the scientific world for the courses of education of science teachers.

Key words: Social relations in science, public image of science, scientificism. 


\section{Introdução}

Frequentemente observa-se nas aulas de ciências, tanto entre alunos como entre professores, a existência de visões inadequadas sobre o "funcionamento" das ciências naturais. A idéia de que todo o trabalho científico vise tecnologia, ou que o nível de colaboração no campo da ciência e tecnologia seja desinteressado, ou ainda que os cientistas possuam vocação e apresentem dedicação sacerdotal ao trabalho científico denotam, entre outros, aspectos que necessitam ser seriamente trabalhados no contexto escolar, em diferentes níveis.

Ao se considerar que no campo científico-tecnológico encontram-se muitas das causas daquilo que nos leva a ter hoje uma "sociedade de risco" (Beck,1992), percebemos que dos estudos da sociologia da ciência podem advir significativas contribuições para a educação de professores das disciplinas cientificas, no sentido de que podem contribuir para o desenvolvimento de posturas criticas sobre o mundo das ciências e da tecnologia. Desta abertura de espaços para a sociologia, na formação de professores e, conseqüentemente, no trabalho escolar pode-se obter mais efetividade em uma educação voltada a oferecer bases para o exercício de cidadania.

O presente texto é descritivo e analítico, no qual se procura alternar perspectivas, que vão da abordagem de impactos das ciências naturais nas sociedades e a explicitação de elementos sociais internos às estas ciências.

\section{A elevação de status das ciências naturais e a cientifização da sociedade}

Logo após a sua proposição inicial por August Comte, ainda na segunda metade do século XIX, a doutrina positivista já havia conquistado um espaço que transcendia a academia. Diferentemente da filosofia metafísica, os positivistas procuravam dar um tratamento científico às questões sociais, o que na prática significava a tentativa de construção de uma "física social".

Assim como o liberalismo, a perspectiva positivista privilegiava a racionalidade científica, mas com outras ênfases:

Os positivistas eram evolucionistas, $e$ para eles a sociedade ainda deveria alçar-se a níveis mais elevados de racionalidade, o que seria alcançado mediante a descoberta das leis, mecanismos e procedimentos técnicos que desvelariam um futuro que se supunha preordenado pelo processo evolucionário. (Schwartzman, 1980).

Os ideais do cientificismo positivista representaram uma tentativa elaborada de aproximação da ciência e sociedade, e se manifestaram na política, na organização de instituições governamentais e até mesmo religiosas (Comte, 1988).

Mas, o reconhecimento da maturidade e do status alcançado pelas ciências naturais não se limitava à Europa, embora fosse aquele continente o mais representativo da ciência mundial até as primeiras décadas do século XX. Em 1906, Thorstein Veblen publicou na revista American Journal of Sociology um artigo intitulado "O lugar da ciência na civilização moderna”, no qual enfatizava a existência de certa inclinação da sociedade norte-americana daquela época para as explicações impessoais no lugar das antropomórficas, e justificava 
este fato pelo surgimento da indústria e da tecnologia. Ao estudar o mundo acadêmico norte-americano:

"Veblen iluminou os escuros desvãos do sistema universitário com sua tocha sociológica, comparando os acadêmicos a outros guardióes do conhecimento esotérico, como os paᄀdres, xamãs, curandeiros, observando que, dentro do grupo, esse conhecimento esotérico é considerado verdade universal..." (Burke, 2003).

Esta citação sobre Veblen ilustra como determinados aspectos do mundo científico chegavam à grande sociedade. As chaves do conhecimento eram guardadas pelos acadêmicos, mas é de se supor que as conquistas da ciência, seus produtos e resultados, ocasionalmente ficavam visíveis para a sociedade, e quando isto acontecia eram fornecidas pistas sobre como tais conquistas se realizavam. Assim, como ainda acontece, restava à sociedade, leiga em matéria de ciência, constituir uma imagem de como a ciência funciona, pois isso guarda certa importância. A imagem do que é científico é socialmente utilizada por várias razões, uma delas parece estar no fato de a sociedade julgar que o "científico" funciona como meio contundente de se conquistar credibilidade. Por outro lado, Veblen também percebia elementos que constituíam certa imagem do poder da ciência: grupo fechado que internamente compartilha conhecimentos nos quais acreditam firmemente.

Max Weber, um dos fundadores da sociologia moderna, escreveu, em meados da primeira década do século XX, um texto no qual analisava as contribuições e os perigos do pensa- mento científico para as sociedades. Em "Ciência e política: duas vocações", Weber via a ciência como propulsora da tecnologia e esta como controladora da vida. Para ele, a ciência contribuía socialmente para a construção de métodos de pensamento e para o adestramento do pensar e "ganho de clareza”. Entretanto, a prática científica parecia ser assumida por Weber como disseminadora de um tipo de racionalidade "formalista", que se traduzia no ajuste entre meios e fins, e não em uma postura crítica em relação aos fins (Weber, 1989).

Weber percebia uma relação entre a especialização científica e a vocação. Para ele a ciência, já no início do século $\mathrm{XX}$, havia chegado a tal grau de especialização que somente aquele que possuísse uma grande propensão interior para alcançar qualquer coisa de verdadeiramente valioso no domínio científico entraria nesse mundo.

Em suas análises a respeito da sociedade capitalista moderna, Max Weber introduz o conceito de "racionalização" para descrever o processo de desenvolvimento existente nas sociedades modernas.

Esse processo caracteriza-se pela ampliação crescente de esferas sociais que ficam submetidas a critérios técnicos de decisão racional, isto é, a critérios de adequação e organização de meios em relação a determinados fins, como acontece, por exemplo, na urbanização das formas de existência, na tecnificação do tráfego e da comunicação. O planejamento e o cálculo foram tornando-se, cada vez mais, partes integrantes de procedimentos envolvendo questões administrativas. (Gonçalves, 1999). 
Com os trabalhos de Weber nasce uma nova perspectiva para os estudos sociais. Diferentemente da sociologia positivista de Auguste Comte e da centralidade historicista de Karl Marx nas questões sócio-político-econômicas, a perspectiva weberiana procurava distanciar-se das ciências naturais como modelo para as ciências sociais. Suas análises, que resultaram na constituição teorias (como a da burocracia), categorias (como a da racionalidade instrumental) e perspectivas (como a da ética protestante), tinham como pano de fundo a idéia de que as idéias são socialmente situadas, formadas por visões de mundo ou estilos de pensamento.

\section{Tentativas de se dizer o que é ciência e o que não é}

Uma análise destoante da aceitação das ciências naturais como modelo para as demais áreas de conhecimento foi feita por Edmund Husserl, no final da década de 1930. Ele divulgou sua análise em um dos seus mais importantes textos, "A crise das ciências européias e a Fenomenologia Transcendental", que viria a ser publicada no início da década de 1950. A crise a que ele se refere neste texto tem um sentido ético e social, e diz respeito ao fato de que as ciências naturais, ao não se interessarem pelos seus fundamentos, desprezam a subjetividade humana. Nos dias atuais, talvez seja difícil de imaginar aquilo que Husserl enfatizava como "atitude natural" no mundo, ou aquilo que seja "experiencial”, que possibilita narrativas. A razão desta possível dificuldade está no fato de que já se tornou bastante natural a predeterminação científica, técnica e objetiva do que é para ser sentido em muitas experiências genuinamente humanas.
Porém, a resistência da visão cientificista era grande. Na manifestação formulada pelos intelectuais do Círculo de Viana, no texto A Concepção Científica do Mundo, de 1929, assinado por Hans Hahn, Otto Neurath e Rudolf Carnap, é proposta a rigorosa eliminação da metafísica do domínio do pensamento racional e o estabelecimento de uma ciência unificada baseada na experiência imediata. Assim, por exemplo, tanto as formulações matemáticas quanto as teorias sociais teriam que passar pelos crivos da confirmabilidade e testabilidade a fim de se concluir se seriam significativas ou não, isto é, se seriam proposições ou pseudoproposiçoes vazias. Mas, os positivistas lógicos encontraram fortes oposições. Karl Popper, que freqüentava reuniões do Círculo e que chegou a ser considerado como alinhado ao pensamento deste, orgulhava-se de ter derrubado estas idéias por meio dos seus princípios de falsificabilidade e refutabilidade (Giddens, 1978; Freitag, 1986). Nota-se que as preocupações dos positivistas lógicos centravam-se, aparentemente, em questões internas das ciências naturais e culturais, mas as necessidades impostas pelo exame de determinadas teorias e conceitos fazia a perspectiva externalista ser ressaltada.

Uma das mais significativas contribuições de Popper à filosofia da ciência está no seu critério de demarcação entre ciência e não-ciência. Segundo Martins (1986), o objetivo original do seu critério era o de fornecer uma clara distinção epistemológica entre ciências empíricas, como a física, e pseudo-ciências como a astrologia, psicanálise e marxismo. Mas, pelo fato de a própria teoria de Popper para a demarcação ser impositiva, não se pode tentar falseá-la mesmo através 
de casos, situações, problemas etc. que surgiram ao longo da história da ciência.

No primeiro texto de grande impacto de Popper, A lógica da descoberta científica, que viria a ser publicado em inglês vários anos depois da primeira versão publicada em alemão, em 1934, e que é tido como um clássico da filosofia contemporânea da ciência, há um ataque contundente ao positivismo, especialmente ao método indutivo em ciências naturais. Popper propõe o verificacionismo e o falcificacionismo, o que possibilitaria um olhar diferente para o grupo social dos cientistas naturais: ao invés de procurarem confirmar ou corroborar teorias, eles deveriam procurar falseá-las, isto é, submetê-las a testes críticos, pesados. Assim, a sobrevivência da teoria falaria apenas da sua aceitação provisória.

Em seu livro $A$ sociedade aberta $e$ seus inimigos, de 1946, Popper fala sobre o "fardo da civilização" e a "sensação de deriva" daqueles que pertencem ao mundo civilizado, e descreve a perda de significados causada pela sociedade abstrata, que reduz os contatos pessoais e aumenta a distancia entre o homem e a natureza (Popper, 1987). Essa percepção de distanciamentos, que Popper também vira no cientista natural, viria a ser determinante para os rumos da obra de Paul Feyerabend no campo da epistemologia das ciências naturais (Feyerabend, 1991). Ainda neste texto, Popper sugere que a melhor caracterização das ciências vem de seus métodos e não dos seus resultados. Para ele, a "objetividade científica” vem do caráter público e social do método científico, e a imparcialidade do cientista individual não é o que origina a objetividade, mas é resultado da ciência organizada, institucionalizada.
Tanto a posição indutivista quanto a objetivista foram se difundindo nas sociedades mundo afora como modos válidos de produzir conhecimentos cotidianos. Embora tenham ocorrido grandes esforços de epistemólogos para deslegitimar a indução como uma forma científica de conhecimento, e também esforços para tornar aposição objetivista mais equilibrada, no imaginário popular estas posições foram se tornando sinônimos de cientificidade.

O pensamento de Popper encontra similaridade com o de Gaston Bachelard em pontos como: a filosofia científica construída a partir da física, principalmente; a historicidade descontínua do saber científico; a objetividade como produto de uma construção; a impossibilidade da verdade ou do conhecimento absoluto; a mutação contínua dos métodos; a necessidade de pressupostos teóricos para a criação científica; a razão como origem da ciência e não a experiência empírica; a ênfase a uma razão polêmica e inventiva; a valorização do erro como recurso para reorganização do avanço do saber e a transitoriedade das teorias (Jupiassú, 1976).

Para Bachelard o objeto científico nunca se expõe completamente, uma vez que ele está sempre sendo construído, pois não é apreendido, esgotado, a partir da experiência imediata. Ele sustenta que o universo científico é abstrato-concreto, pois as suas caracterizações vêm de um plano teórico e o objeto é tornado real ao ser estudado. Mas, este real não é plenamente alcançado devido às resistências da própria objetivação, que é construída, reconstruída, não esgotada. Assim, na sua epistemologia, Bachelard postula o inacabamento do conhecimento, mas, ao fazê-lo, ele admite que a objetividade 
científica, tal como tradicionalmente concebida, que identifica pensamento e mundo, não existe.

É interessante observar que na perspectiva trivial de conhecimento, amplamente difundida na sociedade, a objetividade possui alto status. Mas, trata-se de uma objetividade que propicia a verdade, o definitivo. Ela também está associada à quantificação, à previsão e ao controle.

Em 1938, o sociólogo norte-americano Robert Merton publicou o texto "Ciência, Tecnologia e Sociedade na Inglaterra do Século 17" no qual analisava a institucionalização da ciência neste período e também o papel da ética puritana. Segundo Pessoa (1993), Merton percebeu uma relação direta entre a religião de vertente puritana e a produção de certas normas de conduta que favoreciam a produção científica. A influência do contexto social sobre o trabalho científico é até os dias atuais frequentemente negada, minimizada ou desconsiderada. Mas, à medida que a sociedade tem mais acesso aos tipos de trabalhos científicos e às suas eventuais conseqüências, ela pode colocar obstáculos às pesquisas científicas.

Em um artigo 1942, Merton propôs a idéia de que a ciência possui uma base ética, interna, que lhe permite ser institucionalizada e promover a produção de conhecimento certificado (Pessoa, 1993). Essas normas são:

I) "universalismo", a aceitação ou rejeição de enunciados científicos não deve depender das circunstâncias pessoais ou sociais do cientista;

II) "comunalidade", os avanços científicos são produtos de colaboração social e assim devem ser acessíveis a toda comunidade de cientistas;
III) "desinteresse", a atividade do cientista não deve visar ao interesse próprio, como acontece excepcionalmente em casos de fraude;

IV) "ceticismo organizado", o cientista deve suspender temporariamente suas opiniões e juízos de valores, e duvidar de tudo.

À medida que as ciências naturais foram se desenvolvendo, as "normas" propostas por Merton mostraram-se equivocadas ou incompletas para explicar fatos que ocorriam nas comunidades cientificas mundo afora. Plágio, fraude, boicote, rivalidade, falta de cooperação, tentativas de alianças espúrias, entre outros aspectos, provocaram olhares mais críticos para a conduta de cientistas e de comunidades cientificas. Por exemplo, o universalismo, mesmo no caso das ciências naturais, na qual este aspecto parece nítido e consensual, não esteve imune à guerra fria entre a antiga União Soviética e os EUA. Livros didáticos de física soviéticos exaltavam enunciados científicos formulados por cientistas daquele Estado e minimizavam, o quanto podiam, as contribuições norte-americanas. Os livros europeus e norte-americanos, por outro lado, jamais citavam certos feitos da ciência soviética. A comunalidade é um conceito que está longe de ter o perfil suposto por Merton. Os cientistas competem mesmo dentro de seus departamentos e a colaboração é tanto mais realizável quanto menor for a possibilidade de concorrência ou maior for a chance de co-autoria em artigos. O desinteresse, por sua vez, não aparece como em outras épocas, porque o cientista de hoje, a par de seu gosto pelo assunto que trabalha, é movido por publicação, 
por possibilidades tecnológicas e de obtenção de recursos para suas pesquisas, por melhor posição no campo científico. O ceticismo organizado, da maneira como Merton o colocou, também é algo gera controvérsias. O cientista de hoje tem sido cobrado cada vez mais para olhar com responsabilidade para as suas pesquisas, pois ele é, normalmente, o primeiro a perceber possibilidades tecnológicas daquilo que investiga.

As críticas aos pontos de vista defendidos por Merton foram grandes. Em textos posteriores ao de 1942, Merton argumentava que vinha sendo sistematicamente mal interpretado, pois o que ele desejava enfatizar com as suas "normas" era o fato de os cientistas terem que lidar com algo que sempre almejavam (universalismo, comunalidade, desinteresse e ceticismo organizado), mas que era muito difícil de ser conquistado.

Em 1968, Merton, trabalhando no problema da estratificação nas ciências, tentava verificar o quanto o mundo científico tinha de universalista na maneira que distribuía créditos. Seu estudo resultou no texto intitulado "O efeito Mateus em ciência”, no qual ele argumenta que em casos de descobertas independentes, ou mesmo de colaboração, o mais eminente de dois ou mais cientistas leva o crédito, mesmo se aquela pessoa participou pouco do trabalho (Cole, 2004). O efeito em si tende a ter interpretações menos contestadoras dentro das comunidades científicas, pois os participantes do "jogo científico" parecem, aos olhos de fora, aceitar bem suas regras tácitas. Porém, isto que pode ser normal para os cientistas é utilizado por outros com o propósito de mostrar que aquele grupo é um grupo social, que apresenta comportamentos idênticos a outros, onde ocorrem disputas, onde há poder em jogo, hierarquia etc. No entanto, trabalhos sérios, que tentam evidenciar e analisar o funcionamento social de grupos científicos, e que são de interesse para a cultura científica, têm o seu espaço disputado por textos que tiram proveito do "mercado" existente no enfraquecimento da autoridade científica.

\section{As ciências durante a segunda guerra mundial: poder máximo}

Um dos cientistas naturais que mais cedo se comprometeram explicitamente com a perspectiva social da ciência foi John Desmond Bernal, que expressou isto em seu texto "The social function of science" (Bernal, 1939). Bernal, que era físico e um ativo marxista, propunha que a atividade científica fosse reorganizada de maneira que se tornasse capaz de responder às verdadeiras necessidades sociais. Em suas palavras:

...para o Marxismo, compreensão é inseparável de ação, e a apreciação da posição social da ciência conduz, em um país socialista, como a URSS, a uma conexão orgânica da pesquisa cientifica com desenvolvimento de uma indústria socializada e a cultura humana. A organização da ciência em países capitalistas tem gradualmente se moldado a serviço dos grandes negócios comerciais, mas pelo fato desse processo não ser aceitável seu resultado é pobre e incrivelmente desperdiçado. Em qualquer caso, produção movida por lucro não pode nunca desenvolver as plenas potencialidades da ciência, exceto para propósitos destruidores. A compreensão Marxista da ciência a coloca em pratica a serviço da comunidade e ao mesmo tempo faz a própria ciência ser parte da 
herança cultural de todo o povo e não de uma minoria artificialmente selecionada (Bernal, 1937).

As idéias de Bernal surgiram em um momento em que a Europa assistia a ascensão do nazismo na Alemanha, e aquilo que ele destacava nos seus textos seria muito visível nos anos seguintes. Mas, se de um lado as idéias de Bernal podiam ser combatidas por colocarem explicitamente a ciência a serviço de uma ideologia de esquerda, de outro o mundo veria parte da ciência alemã ser colocada a serviço de uma ideologia de ultra-direita e parte ser desmantelada por se negar a desempenhar tal papel.

Durante a segunda guerra mundial a ciência mundial foi desafiada de várias maneiras, tanto no campo das soluções que poderiam vir através da tecnologia quanto no terreno da ética, da moral e da responsabilidade social dos cientistas. Como expressão bastante significativa de tipos de problemas que muitos cientistas se recusaram a assumir como seus, ou de problemas que indevidamente eles abraçaram, é interessante destacar aqui algumas passagens do livro "Os cientistas de Hitler: ciência, guerra e o pacto com o demônio", do historiador e jornalista inglês John Corwell (Cornwell, 2003).

Fritz Jacob Haber era um cientista alemão de ascendência judia. Em 1892, ele se converteu ao luteranismo e abandonou o seu nome do meio. O talento de Haber na pesquisa em química era ímpar. Na primeira guerra mundial Haber foi figura central no esforço de guerra alemão para a produção de explosivos, que estivera ameaçada porque a Inglaterra passou a bloquear todos os navios que iam do Chile para a Alemanha com cargas de salitre, que era a matéria prima que os alemães necessitavam para a obtenção dos compostos químicos que necessitavam. Haber liderou as pesquisas para sintetizar a molécula de amônia e a produção de ácido nítrico em larga escala, assim, em 1915 a Alemanha era auto-suficiente na produção de explosivos. Mas, o mundo científico não conhecia Haber somente pelas suas publicações, as suas ações também foram denunciadas. Com a derrota da Alemanha na primeira guerra, Haber, que fora procurado para ser levado a julgamento por crime de guerra, fugiu. Entretanto, em 1918, sob protestos de cientistas de várias partes do mundo, ele recebeu o premio Nobel de química. Mas, seus feitos não pararam por aí. $\mathrm{Na}$ segunda guerra, Haber, perfeitamente alinhado ao nazismo, era figura expoente na máquina de guerra alemã, tinha Otto Hahn como um grande colaborador, e contribuiu de diversas maneiras para o poderio bélico alemão, como, por exemplo, no desenvolvimento de gases adequados para o extermínio de judeus nos campos de concentração. Em 1944, em plena guerra, Otto Hahn ganhou o prêmio Nobel de química, por seus trabalhos em fissão nuclear.

O envolvimento de cientistas em projetos bélicos durante a segunda guerra mundial foi grande. Os casos mais famosos, como o Projeto Manhattan, que resultou na fabricação da bomba atômica nos EUA, ou o desenvolvimento de foguetes na Alemanha, ou ainda o desenvolvimento de radares na Inglaterra, ocuparam os maiores espaços na mídia mundial; mas os casos de trabalhos científicos de menor porte, voltados a esforços de guerra, aconteceram em todas as partes do mundo, em grande escala. 
Embora existam muitas informações sobre a participação de cientistas em projetos dedicados à guerra, ao extermínio de vidas, elas aparecem somente em textos especiais. Nos livros didáticos de ciências, essas informações são omitidas em nome da conveniência de não se mostrar o lado desumano dos cientistas, os seus deslizes, as suas omissões, as suas atitudes antiéticas, imorais. A força da famosa carta enviada ao Presidente Roosevelt por Einstein, em 1939, alertando-o para a possibilidade energética do urânio, é minimizada em nome da grande contribuição de Einstein à ciência, em nome da manutenção do poder da ciência e da sua imagem na sociedade. Assim, os textos de física exaltam os feitos científicos de cientistas como Werner Heisenberg, Hans Geiger, Otto Hahn, Robert Oppenheimer, Joliot-Curie, Otto Frish, James Chadwick, Edward Teller, Leo Szilard, entre outros, mas não destacam episódios nos quais eles estiveram envolvidos e que exigiram deles posicionamentos responsáveis, éticos, moralmente aceitáveis, os quais, em nome do "agir-com-respeito-a-fins", eles não foram capazes de adotar.

As atitudes de cientistas e comunidades científicas durante a segunda mundial e nas guerras posteriores merecem muita atenção de pesquisadores da área da sociologia da ciência. A segunda guerra mundial significou uma amarga amostra da capacidade humana em desumanizar-se, de várias maneiras, por vários meios. Ela foi parte dos extremos que Eric Hobsbawm tão apropriadamente descreveu e analisou em A Era dos Extremos (Hobsbawm, 2003). Extremos que foram alcançados através de alianças que passariam a ser normais daquela época em diante. A ciência e tecnologia foram abraçadas pela política e pela economia, e a conquista de poder através da autoridade científico-tecnológica passou a ser fato comum. Na guerra do Vietnã, nas décadas de sessenta e setenta, o governo norte-americano tinha muitos cientistas e tecnólogos como empregados de projetos belicistas. Um exemplo era a "Divisão Jason", um instituto com finalidade de pesquisa militar, que tinha entre os seus membros cientistas como Murray Gell-Mann, Eugène Wigner, F. J. Dyson, entre outros (Neves, 1999, p. 220). Mas, mesmo se tratando de cientistas proeminentes, comunidades científicas e a sociedade em geral manifestaram repúdio à adesão deles ao desenvolvimento de armas.

Após a segunda guerra, as investidas contra o comunismo ganharam enormes proporções, principalmente nos EUA e de lá para o resto do mundo. A guerra fria logo se instalou e a tragicomédia do macartismo foi propagada para todos os cantos.

Não foi o governo norte-americano que iniciou o sinistro e irracional frenesi anticomunista da caça às bruxas, mas demagogos exceto isto insignificantes, como o senador Joseph McCarthy, que descobriram o potencial político da denuncia do inimigo interno... (Hobsbawm, 2003).

Ainda antes do desfecho da segunda guerra, houve um ataque ao "bernalismo", isto é, às idéias de John Bernal sobre a relação entre ciência e sociedade. Michael Polanyi, que era médico e pesquisador em físico-química, criou a Society for Freedom in Science, no início da década de 1940, a qual visava à garantia da liberdade criadora nas ciências naturais. Naquele momento, ele investia 
contra a intromissão da ideologia de esquerda na atividade cientifica, mas na década de cinqüenta ele se voltaria contra os políticos e tecnocratas, em geral, que estavam ganhando cada vez mais espaço nas decisões sobre C\&T desde o desfecho da segunda guerra mundial (Stengers, 2002).

Num artigo de 1962, intitulado "A república da ciência”, e que foi publicado na prestigiosa revista "Minerva", Polanyi (1962) argumenta a favor de critérios internos à ciência para as decisões sobre os rumos científicos. Este texto expressa uma analogia entre a organização das ciências naturais e a economia, a qual possui uma dinâmica que dita e é ditada por um mercado, mas, por outro lado, também se embasa em regras. No tópico "ortodoxia dinâmica" do artigo, Polanyi fornece uma idéia geral da república da ciência:

A República da Ciência é uma Sociedade de Exploradores. Tal sociedade se esforça rumo a um futuro desconhecido, o qual ela acredita ser acessível e merecedor de ser conquistado. No caso dos cientistas, esses exploradores se esforçam na direção de uma realidade escondida em nome de uma satisfação intelectual. Eà medida que eles se satisfazem, eles iluminam todos os homens e assim ajudam a sociedade a satisfazer sua obrigação na direção de um auto-aperfeiçoamento intelectual. Uma sociedade livre pode ser vista como sendo totalmente inclinada ao auto-aperfeiçoamento - todo tipo de aperfeiçoamento. Isto sugere uma generalização de princípios governando a República da Ciência. Parece que a sociedade inclinada à descoberta deve avançar no sentido de apoiar iniciativas independentes, que sejam coordenadas por elas mesmas, mutuamente uma à outra. Tal regulação pode incluir rivalidades e respostas contraditórias, as quais, na sociedade como um todo, serão mais freqüentes do que são no interior da ciência. Mesmo assim, todas essas iniciativas devem aceitar, para a sua orientação, uma autoridade tradicional, implementando sua própria auto-renovação cultivando originalidade entre seus seguidores (Polanyi, 1962).

No texto destacado acima, há um esforço de Polanyi para justificar porque a ciência desempenha um importante papel na sociedade e porque ela deve ser auto-regulada e protegida das intromissões externas. A imagem do cientista que almeja a satisfação originada no trabalho criativo é bastante atual, entretanto a visão de que os cientistas iluminam a sociedade, a qual parece ser vista como cientificamente ignorante, é politicamente incorreta para os dias atuais, uma vez que, historicamente, há muitas razões vindas do campo científico e tecnológico que apontam para a necessidade de a sociedade se informar mais e melhor para que possa abandonar a atitude de credibilidade apriorística e de submissão à "autoridade científica". Ademais, é importante observar que este texto de Polanyi foi escrito em uma época em que os antagonismos entre os cientistas naturais e os humanistas estavam num nível bastante elevado.

\section{Cultura científica e cultura humanística}

Em 1959, o físico e escritor Charles Percy Snow publicou um pequeno livro que tratava das barreiras para o diálogo entre cientistas naturais e intelectuais 
da área das humanidades. Em 1963, estimulado pelas reações positivas e negativas ao texto, ele o ampliou e o publicou como "As duas culturas e uma segunda leitura”.

Snow não era sociólogo, mas conhecia bem o mundo científico da física. Possuía experiência de trabalho e convivência com grandes nomes da comunidade científica mundial, como William Bragg, mas também, como alguém que criava na área literária, freqüentava os círculos dos escritores ingleses. Assim, sentindo pessoalmente as conseqüências da dicotomia científico - humanística, possuía autoridade para problematizar o tema. De início, deixa claro que estava falando de cultura científica e cultura humanística como sub-culturas de um sistema maior, que podem ser entendidas como "qualidades e faculdades que caracterizam a nossa humanidade", e ao argumentar sobre os danos de tal dicotomia enfatiza que "a educação científica mata de inanição as nossas faculdades verbais; à linguagem dos símbolos é dado um papel esplêndido, à linguagem das palavras não". (Snow, 1995).

Embora não apresente uma sistematização da questão sociológica da ciência, o trabalho de Snow se configura como uma contribuição de base para se repensar como a formação científica, nos vários níveis, e a divulgação científica geral podem considerar a incomunicabilidade e incompreensão entre a cultura científica e a cultura humanística. Ao final do seu texto, Snow enfatiza:

As mudanças na educação não irão, por si sós, solucionar os nossos problemas. Mas, sem essas mudanças, nem sequer compreenderemos quais são os problemas. As mudanças na educação não estão produzindo milagres. A divisão da nossa cultura está nos tornando mais obtusos do que necessitamos ser. Podemos reestabelecer as comunicações até certo ponto. Mas, como já disse antes, não estamos formando homens e mulheres que possam compreender o nosso mundo tanto quanto Piero della Francesca, Pascal ou Goethe compreendiam o seu. No entanto, com sorte, podemos educar uma grande proporção de nossas melhores inteligências para que não desconheçam a experiência criativa, tanto na ciência quanto na arte, não ignorem as possibilidades da ciência aplicada, o sofrimento remediável dos seus contemporâneos e as responsabilidades que, uma vez estabelecidas, não podem mais ser negadas. (Snow, 1995)

Em 1962, Thomas S. Kuhn publicou a primeira versão do texto "A estrutura das revoluções científicas”(Kuhn, 1975). Nas décadas de sessenta e setenta a literatura internacional e inúmeros congressos no campo da filosofia da ciência expressaram intensos debates entre duas correntes de pensamento, a de Karl Popper e a de Thomas Kuhn, principalmente. Outras vertentes, como a de Imre Lakatos e Paul Feyerabend, ganharam maior expressão à medida que se apresentaram como alternativas às duas tidas como principais correntes (Lakatos \& Musgrave, 1979).

A primeira edição do livro de Kuhn causou grande impacto. Um dos conceitos mais inquietantes trazidos por Kuhn foi o de paradigma: "Considero paradigmas as realizações científicas que, durante algum tempo, fornecem problemas e soluções modelares para uma comunidade de praticantes de uma ciência” (Kuhn, 1975). Mas, esta é 
apenas a primeira indicação do que era entendido pelo autor como paradigma. Ao longo do texto de Kuhn, outras tantas indicações serviriam, segundo Margareth Masterman para tornar o conceito ainda mais difícil de ser compreendido num sentido único. Em seu artigo "A natureza do paradigma” (Lakatos \& Musgrave, 1979) esta autora encontrou mais de duas dezenas de atributos no conceito de paradigma no livro de Kuhn, e classificou-os em três categorias: 1 - Paradigma Metafísico ou Metaparadigma - que abrange um conjunto de crenças, uma visão de mundo; 2 - Paradigma Sociológico - que se trata de uma realização cientificamente reconhecida, uma realização científica concreta, ou um conjunto de hábitos; 3 - Paradigma de Construção ou de Artefato - um manual, uma obra clássica de referencia, um fornecedor de possibilidades de exploração.

As variantes do conceito de paradigma sugerem a necessidade de se considerar de maneira mais enfática a perspectiva social. Na segunda edição de "A estrutura das revoluções cientificas", de 1969, Kuhn acrescenta um posfácio onde procura trabalhar no sentido de explorar a relação entre paradigma e comunidade cientifica. Ele reconhece que a sua primeira definição de paradigma parecia ser circular: "paradigma é aquilo que os membros de uma comunidade científica partilham e, inversamente, uma comunidade científica consiste em homens que partilham um paradigma" (Kuhn, 1975). Kuhn reconhece a dificuldade desta circularidade e nesta segunda edição ele introduz o conceito de matriz disciplinar, que envolve quatro elementos: generalizações simbólicas, partes metafísicas do paradigma, "exem- plares" (que são especificidades de um paradigma), e valores.

Ao se examinar a idéia de matriz disciplinar proposta por Kuhn, a idéia de "generalizações simbólicas" parece não oferecer grandes dificuldades. Elas são representações que envolvem nomenclatura matemática, símbolos lógicos e também aqueles símbolos que denotam grandezas físicas, por exemplo, e que são facilmente reconhecidos pelos membros da comunidade maior de físicos ou por comunidades especificas (físicos nucleares, relativistas, espectrometristas etc.).

Para Kuhn, o "exemplar" é aquele conjunto de procedimentos, exemplos, problemas, experimentos etc. próprio de uma dada área, ou de uma subárea, que todo membro de determinada comunidade conhece porque eles são tidos como pressupostos. Por exemplo, a exploração de um problema de poço de potencial simples, em mecânica quântica, pode ser um pressuposto para qualquer um que se gradue em física. Entretanto, a exploração de um problema de poço de potencial duplo, pode ser um tipo de pressuposto adequado para um especialista em física nuclear. Esses problemas de poço de potencial podem ser considerados "exemplares", na linguagem de Kuhn, nas duas situações.

As chamadas partes metafísicas do paradigma dizem respeito a crenças em certos enunciados que são utilizados pelos cientistas para se comunicarem sobre certos fenômenos. Estes enunciados podem se apresentar na forma de modelos, analogias e metáforas. Eles não precisam necessariamente ser os mesmos para todas as comunidades cientificas quando forem tratar de um determinado fenômeno, mas têm que 
ser adequados, plausíveis. Kuhn cita como exemplo o seguinte enunciado, "as moléculas de um gás se comportam como pequenas bolas de bilhar elásticas movendo-se ao acaso". Trata-se de uma analogia que pode ser julgada ser pertinente ou não. Esta capacidade de os físicos julgarem se a analogia serve ou não para o comportamento de um gás é possível porque eles compartilham uma heurística comum sobre este fenômeno.

O último aspecto da matriz disciplinar de Kuhn, e que é de especial interesse para o presente trabalho, diz respeito aos valores. Kuhn sustenta que os cientistas naturais aderem com maior intensidade aos valores relativos às predições: preferem as quantitativas às qualitativas, julgam que devam ser acuradas e que devam situar-se dentro de uma margem de erro. Além desses, Kuhn salienta os julgamentos realizados por cientistas naturais baseados em simplicidade, coerência interna e plausibilidade. Todos estes são valores de natureza interna às ciências naturais, pertencem ao campo cognitivo e são muito atuais. Mas, Kuhn faz uma autocrítica por não ter considerado na primeira edição de seu livro os valores mais socialmente mais abrangentes. Ele dá como exemplo a seguinte questão, que via como interessante: a ciência deve ou não deve ter uma utilidade social? Mas, não prossegue neste assunto.

Além de história e filosofia da ciência, o texto de Kuhn explora a perspectiva social interna da ciência. Em particular, o conceito de paradigma, com todos os detalhamentos que recebeu no posfácio de 1969, guarda um aspecto básico que diz respeito à fidelidade que o cientista tem com ele. Tal aspecto pode ser interpretado como um obstáculo à consideração de certos pleitos ou objeções vindas do mundo externo àquele dos defensores do paradigma. Por exemplo, o corpo teórico da física nuclear, na perspectiva kuhniana, forma um paradigma, ou uma matriz disciplinar. Um cientista que trabalha neste campo estará propenso a achar inadmissíveis as posições contra o aproveitamento da energia nuclear através de uma usina, por exemplo. Posições como estas são consideradas "externas" à ciência e se forem socialmente aceitas constituem-se, para o cientista praticante da área, em um grau de impedimento de possibilidades de pesquisas dentro do paradigma. Muitos outros exemplos desta natureza poderiam ser lembrados; o campo da biotecnologia, por exemplo, é farto deles.

Mas, alguns aspectos do mundo paradigmático onde os cientistas naturais se encontram, e que merecem ser olhados mais detidamente, são: a) visões de mundo são fortemente ligadas aos paradigmas, b) as defesas da potencialidade de um determinado paradigma não se embasam apenas em valores cognitivos, c) neutralidade, imparcialidade e sentido de comunidade são idealizações do mundo científico.

Para falar sobre as visões de mundo dos cientistas é interessante transitar no terreno da abrangência dos paradigmas na concepção de Kuhn. É fato, dentro do modelo kuhniano, que o trabalho científico exige um tipo de criatividade que deve acontecer dentro das "amarras paradigmáticas”, as quais dizem respeito a conceitos, teorias, métodos de investigação, representações etc. Mas, por outro lado, a cultura científica é uma subcultura de uma cultura maior, e o cientista não se despe desta última quando trabalha em ciência. Isto é, de- 
pendendo do problema de pesquisa que ele está tratando, ele opera com maior ou menor intensidade com "elementos externos" ao aparentemente restrito mundo científico. Do mesmo modo, mas em sentido contrário, o cientista natural tenta evidenciar seu lado científico quando opera em grupos sociais de não cientistas, quando tem que transitar na cultura geral.

Paul Karl Feyerabend, físico e pensador austríaco, pesquisou eletrodinâmica clássica na Universidade de Viena, onde obteve seu doutorado em Física. $\mathrm{Na}$ área de filosofia, foi orientado de Karl Popper, em Cambridge, Inglaterra. Em sua mais importante obra como filósofo - Contra o Método - Feyerabend critica as análises da natureza da ciência que normalmente aparecem e que excluem as características humanas do fazer científico. Assim, seu trabalho não resulta em uma análise da metodologia científica, porque ele não acreditava nela como tal, mas resulta na ênfase às limitações, exceções e, principalmente, ao dogmatismo reinante na atividade científica, e que não são explicitados e, portanto, não criticados. Feyerabend também critica a idéia do conhecimento científico ser obtido independentemente da subjetividade humana e das circunstâncias e contextos culturais:

a maneira como os problemas científicos são abordados e resolvidos depende das circunstâncias em que surgem, os meios (formais, experimentais, ideológicos) disponíveis na altura e os desejos daqueles que com eles trabalham. Não existem condições duradouras que limitem a investigação científica. (Feyerabend, 1991).
Sobre o cientista situado num contexto cultural, conforme Pinto (2002), Feyerabend diz que os cientistas:

...além de pecadores por contrariarem "o método científico" e de oportunistas por utilizarem propagandas para convencerem os oponentes de suas idéias, não são neutros culturalmente, ou seja, não podem se libertar das crenças não científicas a que são submetidos durante sua formação. (Pinto, 2002).

Ao evidenciar como aspectos culturais, sociais e humanos fazem parte da atividade científica, ao argumentar a favor da posição de que a ciência não é necessariamente superior a outras formas de conhecimento, Feyerabend denuncia o "engodo do método científico", e em seu lugar apresenta possibilidades que, desde o principio da década de setenta, vêm sendo rotuladas como "vale tudo" e "anarquismo epistemológico". Mas, se por um lado o anarquismo de Feyerabend é vulnerável por combater um método científico rígido que na prática científica não existe (Chalmers, 1999), por outro ele combate a pretensão de rigidez, a desconsideração de saberes não científicos, a falta de relevância da subjetividade na atividade científica, e estimula o cientista a ser crítico sobre seus posicionamentos metodológicos.

Ao reconhecer a existência de limites em sua metodologia de pesquisa o cientista (e o filósofo da Ciência que tenta compreender os seus procedimentos) estará mais atento a problemas éticos, estéticos, políticos, gnosiológicos, em meio a tantos outros, que seu trabalho pode gerar, se considerado por um ponto de vista dogmático. Se estiver consciente deste aspecto da natureza de sua prática, o 
cientista terá maior oportunidade (o que não implica necessariamente que o fará) de explorar seus pressupostos, questionando as balizas de seu exercício, com o intuito de contribuir para seu alargamento e qualificação.(Pinto, 2002)

\section{Embates entre sociólogos e cientistas}

Até o início da década de 1970, os sociólogos acreditavam que fatores sociais afetavam, quando muito, apenas os aspectos periféricos do conhecimento científico. O fato de analisarem a vida de cientistas através de entrevistas, narrativas etc. configurava aquilo que ficou conhecido como "programa fraco". Mas, em meados da década, o filósofo David Bloor, o sociólogo Barry Barnes e o historiador Steven Shapin, da Universidade de Edimburgo, na Escócia, introduziram uma nova abordagem, que ficou conhecida como o "programa forte" dos estudos sociais do conhecimento. Nesta nova abordagem interessava analisar como o conhecimento científico é produzido.

No radicalismo do programa forte, o relativismo é levado às últimas conseqüências. Bloor, baseado na idéia de que não se pode separar a natureza da sociedade, considerou a "origem social" como a noção que denota o fato de que a cognição humana sempre reflete a ordem social. Como implicação, temse o fato de que a análise do certo ou errado nas explicações cientificas deve seguir métodos similares. Conseqüentemente, não se pode atribuir uma causa puramente racionalista para uma teoria considerada verdadeira e uma causa social para a teoria rejeitada.

A reação de muitos cientistas ao programa forte aconteceu no sentido de considerar que os seus propositores tomam, erroneamente, o conhecimento científico como um sistema de crenças, como se julgamentos racionais e verificação empírica não fizessem parte da seleção do que é tomado como verdadeiro. Os defensores do programa forte, por seu lado, declaram que apenas tentam julgar a ciência utilizando uma abordagem científica.

O fato de as ciências naturais serem referência para outros campos de conhecimento foi marcante em quase todo o século vinte. Mas, a busca de identidades epistemológicas pelas ciências humanas também foi nítida neste século e aconteceu ao lado de uma crescente crítica à impregnação da visão positivista das ciências naturais em todos os campos do conhecimento. Bruno Latour, Steve Woolgar, Michael Mulkay e Karin Knorr Cetina, entre outros, são alguns dos autores que se inserem dentro da perspectiva do "programa forte".

Mas, em meados da década de noventa, o programa forte da sociologia da ciência foi objeto de um episódio de repercussão mundial. Alan Sokal, um físico, professor da New York University, publicou na edição da primavera/verão, de 1996, da "Social Text", uma revista esquerdista de crítica cultural, dedicada sobretudo ao "pós-modernismo", um ensaio intitulado "Atravessando as Fronteiras: em Direção a uma Hermenêutica Transformativa da Gravidade Quântica". Logo depois, Sokal publicou em outra revista, a "Língua Franca", um artigo intitulado "Um Físico faz Experiências com Estudos Culturais". Nesse artigo, ele explica que o texto mandado para "Social Text" era uma paródia feita em cima do que e de como falam os sociologistas da ciência; era, segundo 
ele, uma piada repleta de frases sem sentido, para dar a impressão de que estava realizando análises em campos humanísticos valendo-se da cientificidade da física. Com isso, Sokal pretendeu demonstrar como os pesquisadores do campo da sociologia não possuem critérios e qualificação adequados para julgar o que é científico ou para dizer como as ciências naturais funcionam ou deveriam funcionar.

O episódio Sokal não contribui para o aprimoramento das relações entre as ciências humanas e as ciências naturais, pois o rumo que o embate teve deveu-se à utilização de uma estratégia racionalmente condenável. Sensacionalismo e disputa por autoridade foi o que se viu, vez ou outra, por muitos meses em grandes jornais e na internet.

\section{Ciência e tecnologia: um grande negócio?}

Desde o final do século XX, o mundo assiste um impressionante crescimento do setor científico-tecnológico. Mais que em nenhuma outra época, está muito evidente que as ciências têm propiciado tecnologias sofisticadas e que muitas tecnologias têm propiciado mais e melhores ciências. Mapeamento genético, exploração astronômica por telescópio espacial, controle de processos em escala nanométrica e investigação do mundo subatômico com superacelerador de partículas são alguns dos inúmeros exemplos de conquistas recentes.

À medida que grandes invenções científico-tecnológicas acontecem, os mecanismos gerais de divulgação científica ganham mais evidência. Assim, a "venda" da informação científica por meio de revistas, por exemplo, passa a ser um negócio bastante lucrativo e, mais do que isto, os próprios meios de divulgação passam a "cientificar" diversos temas do cotidiano, ou da moda, e um tratamento com pretensão científica é dado a assuntos como a existência de Deus, existência de destino, amor, espiritismo, custo da felicidade e atividade paranormal, entre outros. Esta cientifização de temas acaba por inserir as ciências em terrenos que muitas vezes não lhes são próprios e a sua imagem, junto à sociedade, tende a ficar cada vez mais, e inadequadamente, fortalecida.

Por outro lado, do interior das ciências e de sua relação com o mundo externo surgem problemas de difícil administração. Por exemplo, os cientistas, quando, de alguma forma, são impedidos de seguir as suas trajetórias de trabalho reclamam por liberdade e autonomia. Impedimentos legais que surgem devido a demandas sociais do campo religioso, ético ou moral são vistos por eles como inadmissíveis, pelo menos num primeiro momento. Mas as discussões tomam diferentes rumos, dependendo dos países, da cultura e da participação social aonde acontecem. No Brasil, a chamada Lei de Biossegurança,criada e aprovada depois de muita discussão e decisão do Supremo Tribunal Federal, tenta regulamentar as polêmicas existentes em torno das pesquisas com células-tronco e também na produção e comercialização de organismos geneticamente modificados.

Uma sociedade minimamente educada no campo científico, não apenas no âmbito teórico-conceitual das ciências, mas também no que se refere ao funcionamento da produção científica, ao reconhecimento de interesses e à diferença entre uma visão crítica sobre as ciências e uma visão cientificista, pode exercer o 
dever cidadão de opinar sobre os rumos de pesquisas cientificas quando estas oferecerem riscos à vida das pessoas, ao ambiente natural ou quando forem potencialmente viabilizadoras de discriminações humanas e sociais.

Certamente, à medida que as ciências se expandem novos problemas surgem ou velhos problemas ganham novas vestimentas. O debate sobre a condição de ser cientista necessita cada vez mais ser instalado, pois, seja a ciência produzida com recursos públicos, seja com recursos privados, os impactos sócio-ambientais sempre existirão e caberá à sociedade ficar atenta ao reconhecimento deles, exigir explicações e responsabilização.

Uma ampla compreensão social sobre tipos de relações que envolvem o mundo científico-tecnológico se faz cada vez mais necessária. Aquilo em que muitos não acreditam, a principio, acontece cotidianamente em varias partes do mundo: a fraude científica. No pensamento social, naturalizado, de que no mundo científico todos são bem intencionados não há lugar para o fato de que há casos de cientistas que forçam resultados para gerarem publicações e com isto ganharem projeção e recursos. Mas, diferentemente do escândalo que pode significar uma fraude, existem formas sutis de fazer a pesquisa científica seguir rumos inesperados.

O pesquisador norte americano Sheldon Krimsky em seu livro "Science in the Private Interest" explora casos de vantagens financeiras oferecidas para pesquisadores para darem determinadas orientações a suas pesquisas na área biomédica. O autor mostra (Krimsky, 2003) a existência de rede de interesses que envolve pesquisadores, industrias farmacêuticas, comitê de julgamento de pesquisa e editores de revistas científicas. Embora a participação de grandes empresas no financiamento de pesquisas em instituições universitárias norte americanas tenha sido regulamentada por lei no início da década de 1980, os desdobramentos deste fato tem gerado o que Krimsky chama de privatização da ciência. Ao se conhecer as particularidades deste processo, se pode antever que o problema de orientar a atividade científica para o lucro, como já existe, pode criar situações totalmente incompatíveis com a idéia que historicamente formamos sobre o desenvolvimento do conhecimento.

Exemplos de possibilidades científico-tecnológicas antiéticas existem há muito tempo. A eugenia nazista é um dos casos mais conhecidos, mas com o contínuo crescimento das ciências sempre surgem possibilidades de utilização do conhecimento científico para propósitos imorais. Recentemente, cientistas espanhóis propuseram uma forma de determinação da expectativa de vida das pessoas por meio da análise do tamanho das extremidades de telômeros, que num futuro próximo poderá ser determinada por um exame de sangue. Podemos imaginar que uma descoberta deste tipo poderá induzir o aparecimento de processos discriminatórios como, por exemplo, um preço diferenciado para o seguro de vida de uma pessoa que possua uma expectativa menor de vida. Para que a sociedade se manifeste contrariamente a atitudes como esta é preciso que o conhecimento seja difundido e que se saiba mais a respeito dos interesses que os envolve. 


\section{Conclusão}

Neste texto procurou-se evidenciar aspectos de análises, teorias ou visões sociológicas que atenderam a duas perspectivas básicas: uma, que diz respeito a olhares externos às ciências naturais e outra que diz respeito a olhares feitos através de perspectivas internas das ciências. Embora a passagem pelos autores considerados tenha sido rápida, ela fornece expressões das aproximações e distanciamentos entre uma cultura, a científica, que tende a olhar para a ciência pela visada do seu funcionamento, da sua manutenção e do seu entendimento sobre progresso científico, e a cultura humanística, que tende a ressaltar os problemas decorrentes dos impactos das ciências e da tecnologia na grande sociedade.

Entre os cientistas, é comum a imagem da ciência como um padrão elevado, disciplinado e confiável de conhecimentos. Entretanto, somente um número muito pequeno de cientistas se preocupou em olhar para este padrão criticamente, o que historicamente forneceu elementos confirmadores dele, assim como elementos que contrariam a existência de uma ordem aos moldes daquela que é imaginada. Assim, da própria ciência podem partir duas perspectivas: uma esclarecedora, no sentido que a Teoria Crítica utiliza o termo, e que pode contribuir para os indivíduos se posicionarem frente a determinados problemas como autonomia e liberdade; e outra, conservadora, que é compatível com a imagem pública da ciência, que possui um caráter positivista e que sustenta o mito científico, no qual a palavra da ciência é sempre a certa e final.

Inicialmente, os olhares críticos à ciência, dirigidos por sociólogos, pro- vinham de uma perspectiva externa e, portanto, se atinham aos produtos, que eram julgados provenientes da ciência pela via da tecnologia, principalmente, e também àquilo que se imaginava serem processos confiáveis de conhecimento. Historicamente, por meio dessa visada externa, a ciência tanto foi crucificada como foi enaltecida. Assim, análises internalistas precisavam também ser consideradas para que fosse possível posicionar melhor a ciência dentro da cultura geral.

À medida que cientistas naturais se interessaram por realizar análises sobre o caráter epistemológico, filosófico e social da ciência, eles forneceram aspectos internos, em forma de modelos de funcionamento, que permitiram maior visibilidade sobre os valores que possuem e que externam para justificar seus procedimentos e a abrangência deles.

Se, por um lado, a ciência não deveria julgada pelos produtos tecnológicos que chegam à sociedade, uma vez que ciência não é tecnologia, por outro, por mais complexas que sejam a relações entre ciência e tecnologia, é através da tecnologia, em grande medida, que a ciência chega ou é imaginada pela sociedade. Esse aspecto da relação C\&T tem sido o ponto nevrálgico das análises sociológicas da ciência. Onde entra a subjetividade no trabalho do cientista? Numa perspectiva humanista a resposta é "sempre". Numa perspectiva cientificista a resposta é "raramente". Mas, há que se considerar o problema da demarcação do trabalho científico. Ele não vai somente até onde os resultados concretos permitem ver, sejam eles teorias ou produtos. Ele vai até onde é possível se enxergar suas potencialidades tecnológicas, e não há nenhuma ingenuidade ou deformação 
nesse argumento, uma vez que um dos pontos onde os cientistas mais insistem quando submetem projetos para obter financiamentos são as potencialidades tecnológicas.

Quando a intimidade das ciências naturais é revelada, muitas possibilidades de comunicação com os campos não

\section{Bibliografía}

Bachelard, G. (1978). O novo espírito científico. São Paulo, Editora Abril Cultural.

Beck, U. (1992). Risk Society, Towards a New Modernity. London: Sage Publications.

Bernal, J. D. (1937). Dialectical Materialism and Modern Science. Science and Society, II- 1.

Bernal, J. D. (1939). The social function of science. Londres: Routledge and Kegan Paul.

Burke, P. (2003). Uma história social do conhecimento: de Gutemberg a Diderot.

Rio de Janeiro: Jorge Zahar.

Chalmers, A. F. (1999). O que é ciência afinal? São Paulo: Editora Brasiliense.

Cole, S. (2004). Merton's Contribution to the Sociology of Science. Social Studies of Science, 34/6, 829-844.

Comte, A. (1988). Curso de Filosofia Positiva. In: Os Pensadores: Comte. São Paulo: Editora Nova Cultural.

Cornwell, J. (2003). Os cientistas de Hitler: ciência, guerra e o pacto com o demônio. Rio de Janeiro: Imago.

Feyerabend, P. K. (1991). Adeus à razão. Lisboa: Edições 70.

Freitag, B. (1986). A Teoria Crítica: Ontem e Hoje. São Paulo: Editora Brasiliense. científicos e com a sociedade são percebidas. Mas as portas de acesso ao interior das ciências precisam utilizadas por cientistas e não cientistas, o que parece ser possível à medida que na educação seja enfatizada uma perspectiva cultural das ciências, diferentemente daquela que temos visto e que, quando muito, possui um caráter apenas instrumental.

Giddens, A. (1978). O Positivismo e seus Críticos. In T. Bottomore e R. Nisbet (orgs.). História da análise sociológica. Rio de Janeiro: Jorge Zahar Editor.

Gonçalves, M. A. S. (1999). Teoria da ação comunicativa de Habermas: Possibilidades de uma ação educativa de cunho interdisciplinar na escola. Educação \& Sociedade, 66, Abril.

Hobsbawm, E. (2003). Era dos extremos: o breve século XX - 1914-1991. São Paulo: Companhia das Letras.

Jupiassú, H. (1976). Para ler Bachelard. Rio de Janeiro: Francisco Alves Editora.

Krimsky. S. (2003). Science in the Private Interest. Rowman-Littlefield Publishing Co.

Kuhn, T. S. (1975). A estrutura das revoluções científicas. São Paulo: Editora Perspectiva.

Lakatos, I. \& Musgrave, A. (Orgs.). (1979). A Crítica e o Desenvolvimento do Conhecimento. São Paulo:Cultrix.

Martins, R. A. (1986). A Popperian evaluation of Einstein's theory-plus-method. Manuscrito, 9(2), 95-124.

Neves, M. C. D. (1999). Memórias do invisível: uma reflexão sobre a história no ensino de física e a ética da ciência. Maringá: LCV Edições.

Pessoa JR. O. (1993). Filosofia \& Sociologia da Ciência: Uma Introdução. Aula ministrada na disciplina HG-022 
Epistemologia das Ciências Sociais. CLE - 29/11/93 (notas de aulas).

Polanyi, M. (1962). The Republic of Science: Its Political and Economic Theory. Minerva 1:54-74.

Pinto, A. C. (2002). Tradição cultural, contraste entre teorias e ensino de física. Dissertação de mestrado não publicada, Universidade de São Paulo, Brasil.

Popper, K. R. (1987). A sociedade aberta e seus inimigos. São Paulo: Itatiaia.
Schwartzman, S. (1980). Ciência, Universidade e Ideologia: a Política do Conhecimento. Rio de Janeiro, Zahar Editores.

Snow, C. P. (1995). As duas culturas e uma segunda leitura. São Paulo: Edusp.

Stengers, I. (2002). A invenção das ciências modernas. São Paulo: Editora 34.

Weber, M. (1989). Ciência e Política: duas vocações. São Paulo: Cultrix. 